\title{
Finite element modeling and identification of metallic materials step responses
}

\author{
Zoltán Pólik \\ Balluff Elektronika Kft. \\ Pápai u. 55. \\ Veszprém, Hungary \\ zoltan.polik@balluff.hu
}

\author{
Zoltán Kántor \\ Balluff Elektronika Kft. \\ Pápai u. 55. \\ Veszprém, Hungary
}

\begin{abstract}
The paper deals with the numerical analysis of a gradiometric coil arrangement excited by bandwidth limited step function and the identification of responses of metallic targets placed into the vicinity of the coil system. The simulations have been executed for different target materials, i.e. aluminum, steel, stainless steel and for four fictive materials differing systematically from the three real target materials in their magnetic permeability and the electrical conductivity. It was found that the changing of the magnetic permeability has a significant influence to the step response when the electrical conductivity of the target material is low, however it has a less influence to the response of the target for high-conductivity materials. It has been proved that the step response of a metallic target contains relevant information about the target material and the distance between the coil system and the target.
\end{abstract}

Keywords-Sensors, finite element method, metals, step response

\section{INTRODUCTION}

Coils and coil systems play a very significant role in several sensing applications, for example in non-destructive testers, metal detectors, inductive proximity sensors and magnetic field sensors [1]. In most of these devices the data acquisition based on the classical approach of the proximity sensing, which is an essentially harmonic excitation of a sensing head and the detection of one property of the measuring signal, for example the changing of the amplitude, the frequency or the phase shift resulted by the perturbing effect of an approaching metallic target [2] [3]. The greatest challenge is that the different target materials affect the measurement system differently, finally different amplitude change, frequency change or phase shift can be observed for different target materials for the same sensortarget distance. In conclusion, harmonic excitation based measurement methods contain insufficient information about the target, thus the correct determination of the sensor-target distance for arbitrary metallic target materials, or the determination of the target material for arbitrary sensor-target distance are not possible.

On the other side, numerous methods are emerging to exploit the time domain response of objects to be detected by means of single-pulse or repetitive excitation and time independent analysis of an induction signal captured by a coil or differential coil systems [4] [5]. Transient analysis provides more independent information as compared to the harmonic analysis and may lead to the design of smart sensors with particular properties of material independent or material selective proximity sensing.

This paper deals with the identification of materials on the base of their step response measured by a gradiometric coil arrangement from the aspect of finite element simulations [6] [7] [8]. The advantage of this approach is that in numerical simulations realistic and fictive materials can be used to identify the specific contribution of the materials parameters to the transient response.

\section{MODEL SETUP}

The coil system to be modeled consists of three coils in a gradiometric arrangement. The three coils are coaxially arranged, in three essentially equidistant planes. The model setup can be seen in Fig. 1, where $a$ is $8.2 \mathrm{~mm}, w$ is $0.2 \mathrm{~mm}$, $d$ is $1 \mathrm{~mm}, D$ is $13 \mathrm{~mm}, t$ is $0.1 \mathrm{~mm}, X$ is $1.2 \mathrm{~mm}, X 1$ and $X 2$ are $0.55 \mathrm{~mm}$. The exciting coil in the middle plane is simplified to a disc shaped conductor with uniform current distribution over its cross section, simulating a multiturn planar coil. The sensing coils of the gradiometer are two loop conductors, arranged symmetrically and coaxially with the exciting coil.

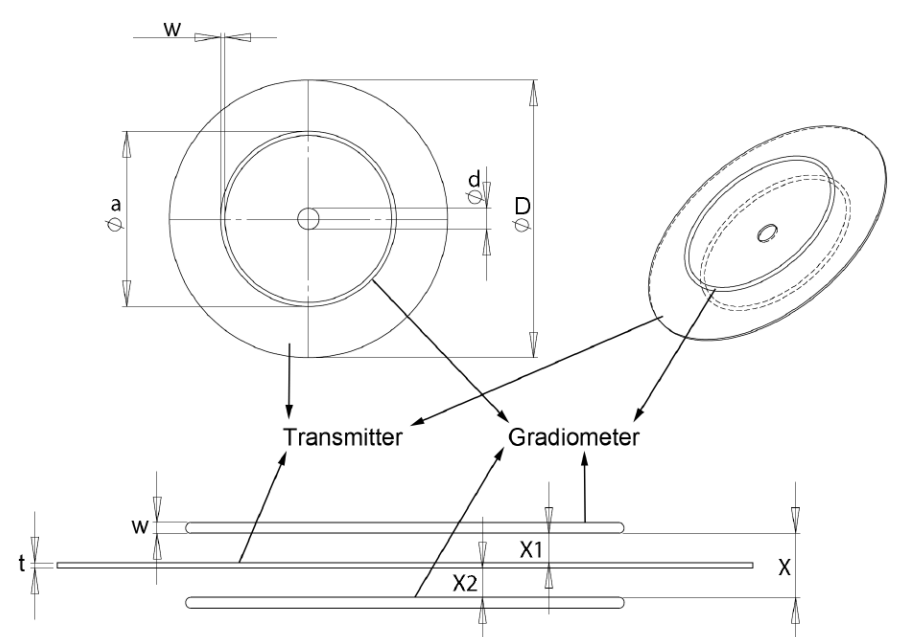

Fig. 1. Geometry of the gradiometric coil arrangement

A metallic object is placed near the coil system where the materials of the target were primarily aluminum, steel and stainless steel, and in order to unveil the specific influence of certain materials properties (e.g. electrical conductivity and magnetic permeability), four "fictive" test materials have also been defined and used in this work. The material 
parameters are listed in Table 1. The Aluminum and steel parameters are typical of $\mathrm{Al}_{\mathrm{x}} \mathrm{Mg}_{\mathrm{y}}$ and $\mathrm{EC} 80$ respectively. Typically low field strengths are applied in inductive proximity sensors, thus in this example the hysteresis characteristics [9] of the magnetic materials have been neglected and have been approximated with the initial permeability of the materials.

TABLE 1

KEY MATERIAL PROPERTIES OF THE TARGET MATERIALS

\begin{tabular}{|c|c|c|}
\hline & Conductivity $[\mathrm{S} / \mathrm{m}]$ & Relative permeability \\
\hline Aluminum & $3.56 \cdot 10^{7}$ & 1 \\
\hline Stainless steel & $2.11 \cdot 10^{6}$ & 1 \\
\hline Steel & $2.11 \cdot 10^{6}$ & 100 \\
\hline Fictive1 & $2.11 \cdot 10^{4}$ & 100 \\
\hline Fictive2 & $2.11 \cdot 10^{5}$ & 100 \\
\hline Fictive3 & $2.11 \cdot 10^{6}$ & 10 \\
\hline Fictive4 & $3.56 \cdot 10^{7}$ & 100 \\
\hline
\end{tabular}

The excitation current of the transmitter coil is a bandwidth-limited step function, which represents a voltage witch on effect. The steady current through the transmitter being $50 \mathrm{~mA}$. The advantage of the application of a step function is, that its spectrum contains the all frequencies below the cut-off frequency, thus the response of the target can be examined in this wide spectral range. The analysis of the step response is also an adequate method for system identification.

\section{RESULTS}

The step responses of the different target materials have been recorded for 2, 4 and $11 \mathrm{~mm}$ sensor-target distance and the results have been compared. In Fig. 2 the step responses of the steel material are shown for these three distance. It can be seen that the amplitude of the curves are decreasing with the increasing distance, moreover the characteristics of the signals are similar and they have a common zero crossing point around $0.9 \mu \mathrm{s}$.

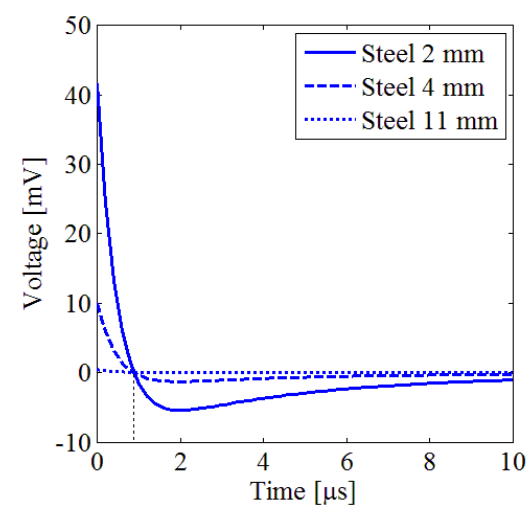

Fig. 2. Step response of steel target at 2, 4 and $11 \mathrm{~mm}$

In the Fig. 3 the step responses of different materials for the same sensor-target distance can be seen where it is observable that the shapes of the curves are different, however their starting points are close to each other.

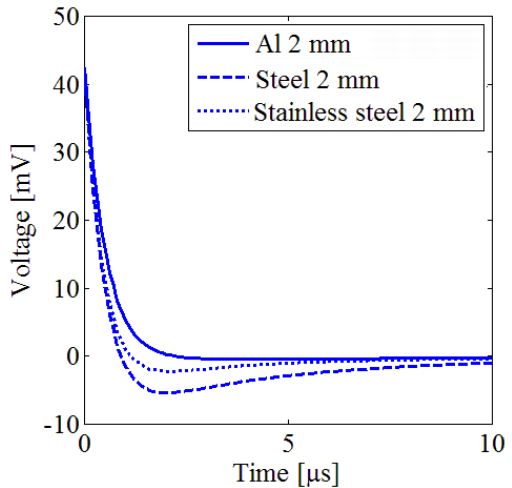

Fig. 3. Step responses of different targets at $2 \mathrm{~mm}$

Based on the first experiences it can be stated that step responses of metallic targets contain relevant information about the target material and the sensor-target distance.

In the full paper, the step responses of the real and fictive materials will be shown and the characteristics of the signals will be compared and evaluated. The special contribution of the magnetic permeability and the electric conductivity to the step responses of the different target materials will be examined.

In order to evaluate the curves an appropriate method will be proposed, moreover the accuracy and the reliability of that method will be presented.

\section{ACKNOWLEDGEMENT}

The work has been supported by the Széchenyi István University of Györ and by the TáMOP 4.2.2/B-10/1-20100010 project found.

\section{REFERENCES}

[1] S. Fericean, R. Droxler, New Noncontacting Inductive Analog Proximity and Inductive Linear Displacement Sensors for Industrial Automation, IEEE Sensors Journal, Vol. 7, No. 11, 2007, pp. 15381545.

[2] K. Fujisaki, High-response inductive electromagnetic sensor, IEEE Transactions on Magnetics, Vol. 39, No. 5, 2003, pp. 2190-2193.

[3] M. J. Gill, Measuring proximity of a metal object, UK Patent Application, GB 2200216 A, 1988.

[4] Y. He, F. Luo, M. Pan, X. Hu, B. Liu, J. Gao, Defect edge identification with rectangular pulsed eddy current sensor based on transient response signals, NDT \& E International, Vol. 43, No. 5, 2010, pp. 409-415.

[5] M. Gopal, Control Systems: Principles and Design, Tata McGrawHill Education, New Delhi, 2006, 971 p.

[6] J. M. Jin, The Finite Element Method in Electromagnetics, Wiley, New York, 2002, 780 p.

[7] D.W. Pepper, J. C. Heinrich, The Finite Element Method, Taylor and Francis Group, New York, 2005, 328 p.

[8] O. Biro, On the use of the magnetic vector potential in the finiteelement analysis of three-dimensional eddy currents, IEEE Transactions on Magnetics, Vol. 25, No. 4, 1989, pp. 3145-3159.

[9] J. D. Jackson, Classical Electrodynamics, Wiley, New York, 1962, $641 \mathrm{p}$. 